15

\title{
Магнитометр на основе структуры высокотемпературный сверхпроводник-эпитаксиальная феррит-гранатовая пленка
}

\author{
(C) E.A. Протасов \\ Национальный исследовательский ядерный университет „МИФИ“, \\ 115409 Москва, Россия \\ e-mail: protasovea@mail.ru
}

Поступило в Редакцию 12 декабря 2018 г.

В окончательной редакции 12 декабря 2018 г.

Принято к публикации 12 февраля 2019 г.

Дано физическое обоснование и предложена принципиальная схема построения магнитометра по способу периодической пространственной модуляции плотности магнитного потока многоэлементной ВТСП структурой и его последующего измерения планарным магнитооптическим устройством с чувствительностью не хуже, чем $10^{-12} \mathrm{~T}$.

DOI: $10.21883 / J T F .2019 .07 .47812 .428-18$

\section{Введение}

Фундаментальным физическим принципом, лежащим в основе создания магнитометра, является способность сверхпроводника, обладающего диамагнитными свойствами, существенным образом влиять на пространственное перераспределение окружающего его магнитного потока. Это приводит к тому, что магнитная индукция на границах сверхпроводника увеличивается многократно, а возникающие локальные поля могут быть измерены с помощью магнитооптического эффекта Фарадея.

В работе [1] были проведены исследования механизма проникновения магнитного потока в тонкопленочные структуры высокотемпературного сверхпроводника (ВТСП) $\mathrm{YBa}_{2} \mathrm{Cu}_{3} \mathrm{O}_{7-\delta}$. Была применена методика визуализации магнитного потока с помощью эпитаксиальных пленок феррит-граната (ЭПФГ), что позволило наблюдать в динамике процессы проникновения и захвата магнитного потока тонкими пленками ВТСП. Установлено, что однородный магнитный поток при наличии сверхпроводящих элементов существенно трансформируется и представляет собой пространственно-периодическую структуру с периодом, равным расположению сверхпроводниковых элементов.

В работе [2] проведены исследования способности периодической ВТСП структуры в виде матрицы сверхпроводниковых чувствительных элементов концентрировать магнитный поток и определены наиболее эффективные способы его измерения. В результате этих исследований было предложено устройство для регистрации малых магнитных полей $\left(\sim 10^{-12} \mathrm{~T}\right)$ - планарный магнитооптический магнитометр.

Наиболее впечатляющие результаты в области магнитометрии с использованием ЭПФГ были получены на пленках с плоскостной анизотропией. Так, в работе [3] описан малогабаритный магнитометр переменных магнитных полей с чувствительностью порядка
$10^{-7} \mathrm{Oe} / \mathrm{Hz}^{1 / 2}$. Такая высокая чувствительность достигнута благодаря большой длине взаимодействия света с магнитооптической (MO) пленкой - $5 \mathrm{~mm}$, что было реализовано в интегрально-оптическом исполнении датчика.

В работе [4] сообщалось об измерении полей порядка $10^{-6}$ Ое в призменной геометрии двукратного прохождения света через МО-пленку с анизотропией „легкая плоскость“. Актуальность исследований по стандартной схеме двукратного прохождения обусловлена перспективой измерения распределений магнитных полей с высоким пространственным разрешением, что невозможно осуществить в интегральной оптике. Измерения проводились с использованием мощного аргонового лазера. С одной стороны, это определило высокую чувствительность из-за значительного коэффициента фарадеевского вращения и относительно низкого уровня дробовых шумов. С другой стороны, массогабаритные показатели и энергопотребление установки были весьма велики, что не всегда приемлемо для потребителя.

Описанный ниже магнитометр состоит из концентратора магнитного потока, роль которого выполняет ВТСП структура и, собственно, магнитооптического измерителя напряженности магнитного поля, использующего эффект Фарадея в прозрачных эпитаксиальных пленках феррит-гранатов. В дальнейшем термин „магнитометр“ будет относиться к устройству в целом, а термин „измеритель магнитного поля“ - к его магнитооптической части.

\section{1. Экспериментальная методика и результаты измерений}

\section{1. Схема измерительной установки}

Для измерения распределения локальных магнитных полей по всей поверхности сверхпроводниковой пленки, в том числе на границе, была создана оптическая схема 


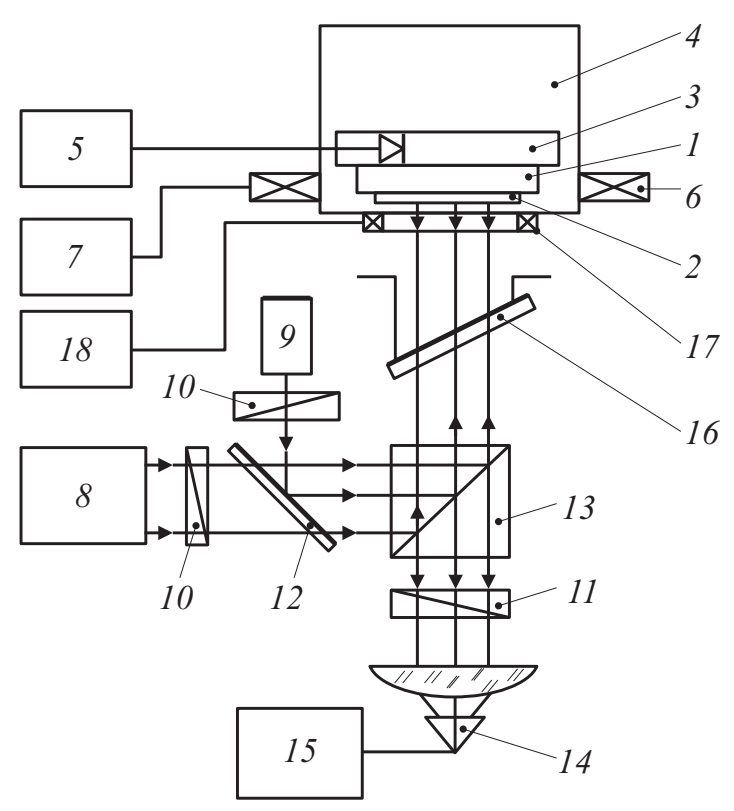

Рис. 1. Оптическая схема измерительной установки (пояснение в тексте).

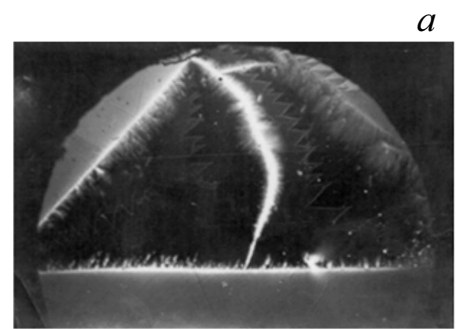

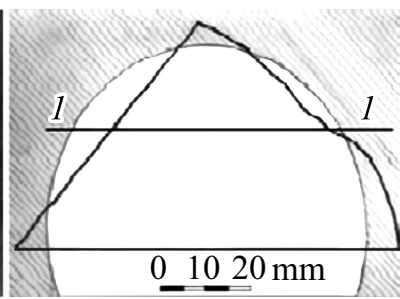

Рис. 2. $a-$ намагничивание во внешнем поле напряженностью 22 Ое; $b$ - форма исследуемого образца.

(рис. 1). Исследуемый сверхпроводниковый образец 1 , находился вместе с пленкой ЭПФГ 2 на медном хладопроводе 3 азотного криостата 4, температура которого измерялась с помощью полупроводникового термометра ТПК 5 с точностью не хуже $0.1 \mathrm{~K}$.

Магнитное поле, перпендикулярное поверхности образца, создавалось системой внешних катушек Гельмгольца 6 , обеспечивающих максимальную напряженность магнитного поля 180 Ое и однородность по образцу не хуже $0.1 \%$. Для создания постоянного магнитного поля катушки подключались к источнику постоянного тока RFT-3218 7.

Оптическая часть установки состоит из источника

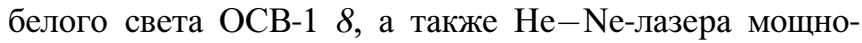
стью $10 \mathrm{~mW} 9$, поляризатора 10 и анализатора 11 . С помощью полупрозрачного зеркала 12 и длиннофокусной линзы лазерный луч, проходя через делительный кубик 13, фокусировался в пятно диаметром около $100 \mu \mathrm{m}$. Отраженный луч света, дважды прошедший через магнитооптическую пленку с зеркальным покрытием 2, попадает на фотоприемное устройство 14 , в качестве которого могут использоваться фотодиод, фотокамера или матрица ПЗС, а затем на селективный усилитель 15 . Наличие полупрозрачного зеркала 12 позволяло одновременно освещать образец белым светом и лазерным лучом. В этом случае изображение намагниченности можно было наблюдать в окуляр микроскопа (на рис. 2 не показан), который устанавливался вместо фотоприемного устройства. Кроме того, изменение угла наклона второго полупрозрачного зеркала 16 в вертикальной и горизонтальной плоскостях позволяло проводить сканирование лазерного луча по поверхности сверхпроводника. Таким образом, можно было визуально выбрать локальное место на пленке ВТСП, намагниченность в котором необходимо измерить. Геометрия наблюдения на отражение позволяет наблюдать границу изменения знака поля в плоскости.

В экспериментах по измерению малых переменных магнитных полей сигнал с фотодиода 14 подавался на вход синхронного детектора. Переменное поле с частотой $f=20-300 \mathrm{~Hz}$ и напряженностью до $60 \mathrm{Oе}$ создавалось при подключении катушек подмагничивания 17 к звуковому генератору Г3-109 [18] и одновременно к опорному входу синхронного детектора. Выходной сигнал с детектора регистрировался самописцем.

\section{2. Измерение локальных магнитных полей и степени концентрации магнитного потока, создаваемого ВТСП пленками}

Поскольку знание концентрационной способности ВТСП пленок является принципиально важным для определения предельной чувствительности разрабатываемого метода измерения слабых магнитных полей, были проведены прецизионные исследования степени локализации магнитного потока, в том числе на краю ВТСП пленки, а также дефекта в виде „трещины“.

В качестве объекта для исследования был изготовлен образец ВТСП системы $\mathrm{YBa}_{2} \mathrm{Cu}_{3} \mathrm{O}_{7-\delta}$ толщиной $0.5 \mu \mathrm{m}$, имеющий форму треугольника (рис. 2), углы которого перекрыты круглой диафрагмой диаметром $7 \mathrm{~mm}$.

На рис. 2, $a$ приведена магнитооптическая фотография образца ВТСП с „трещиной“, которая разделяет пленку как бы на два самостоятельных образца при $H<H_{c}$.

Светлые участки изображения соответствуют проникающему магнитному полю. При этом остальная часть образца обладает значительным диамагнетизмом. Полностью сверхпроводимость исчезает в магнитном поле с индукцией около $40 \mathrm{mT}$.

Профилограммы распределения магнитного потока по образцу, снятые вдоль линии 1-1, изображенной на рис. $2, b$, показывают, что плотность магнитного потока в областях концентрации вихрей достигает практически предельного значения уже во внешних полях около 15 Ое. Левый максимум соответствует краю образца, а правый - области над дефектом в виде „трещины“ (рис. 3). 
Как и следовало ожидать, величина пика от „трещины“ больше, чем пика у края пленки, так как нормальная компонента локального поля „трещины“ создается двумя „круговыми“ токами, текущими по краям „трещины“ в противоположных направлениях. В малых внешних полях, при которых не возникают магнитные вихри, „трещина“ еще не является сквозным дефектом и, следовательно, „круговой“ ток по ней не течет. На картине суммарных полей, создаваемых магнитными вихрями и „круговым“ током, последний выделяется довольно отчетливо в виде узкого пика, который наблюдается на профилограмме слева от „трещины“, изображенной на рис $3, c$.

На рис. 4 представлены результаты измерения величины фотоотклика одноосной пленки висмутсодержащего феррит-граната от напряженности переменного подмагничивающего поля у края пленки ВТСП и на дефекте типа „трещина“.

Поскольку этот дефект не был сквозным, т. е. механически не нарушал сверхпроводящее состояние, а лишь создавал слабую связь между соседними областями, полное разделение по проводимости происходило в полях напряженностью свыше 10 Ое. Этим и объясняется аномальный характер поведения над „трещиной“ (кривая 1) по сравнению с зависимостью у края пленки (кривая 2). Кривая 3 соответствует величине фотоотклика в от-
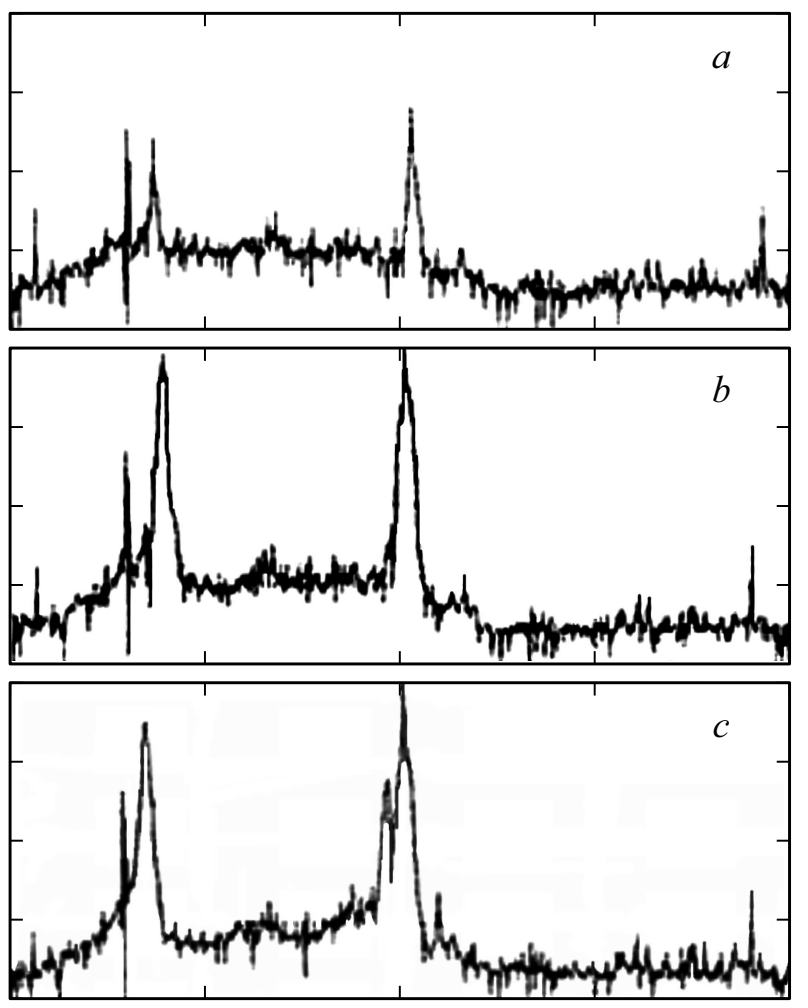

Рис. 3. Профилограммы распределения поля у края ВТСП пленки и над „трещиной“ в магнитных полях: $a-8, b-12$, $c-16$ Ое. Левый максимум соответствует краю образца, а правый - области над дефектом в виде „трещины“ (из работы [1]).

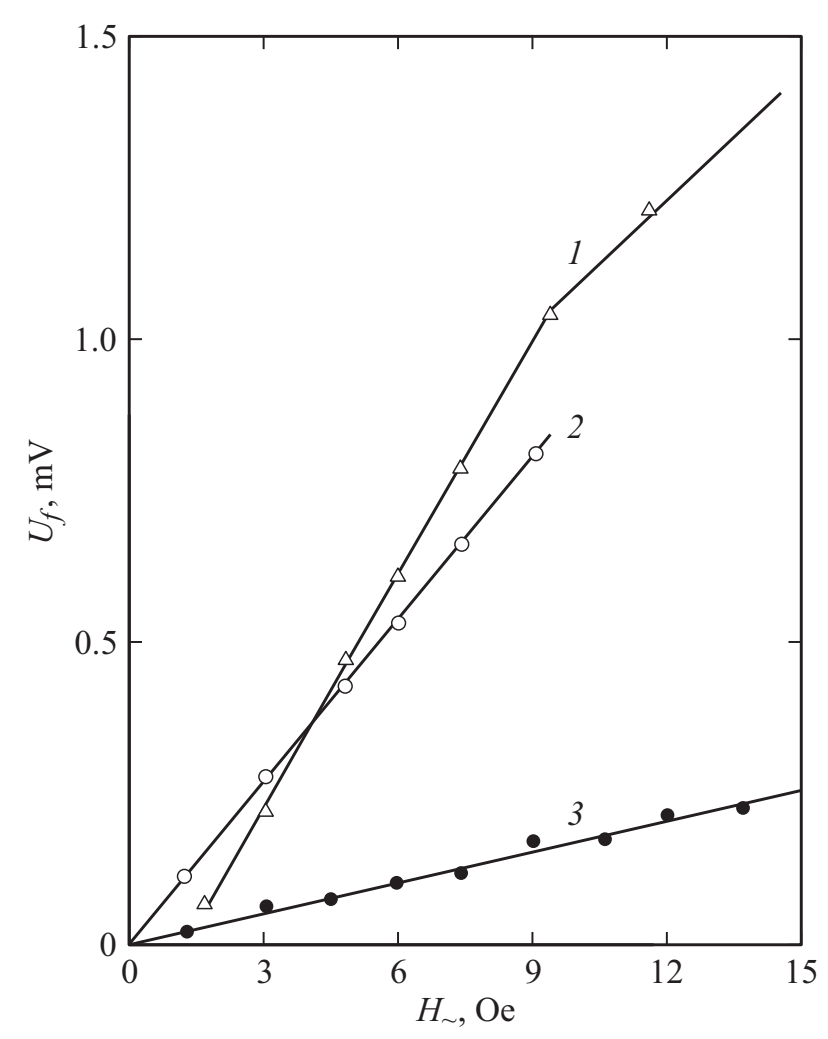

Рис. 4. Величина магнитооптического отклика от напряженности переменного подмагничивающего поля частотой $f=37 \mathrm{~Hz} .1-$ над „трещиной“, $2-$ над краем, $3-T>T_{c}$ (сверхпроводимость отсутствует).

сутствие сверхпроводимости. Измерения проводились с

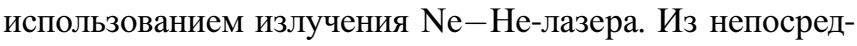
ственных измерений следует 4-5-кратная концентрация поля у края и почти 6-кратная у „трещины“. Отметим, что истинное значение концентрации потока существенно выше, так как площадка, освещаемая лазерным лучом, больше области концентрации магнитного потока примерно на порядок. Несложные расчеты с учетом данных по профилограммам показывают, что реально достижимое значение коэффициента концентрации равно $50-60$.

\section{2. О факторе размагничивания ВТСП пленок}

Принципиальное значение для магнитометрии, использующей эффект концентрации магнитного потока, имеет знание истинного значении фактора размагничивания ВТСП пленок.

Фактор размагничивания определяет значение внутреннего магнитного поля, и, следовательно, сказывается на плотности магнитного потока на границе сверхпроводника, что, в конечном счете, определяет величину коэффициента концентрации. 
Строгое математическое решение задачи о влиянии формы намагниченного тела на его размагничивающие свойства существует для образцов эллипсоидальной формы. Образцы в виде дисков могут быть отнесены к классу сфероидальных образцов при условии, что толщина диска значительно меньше его диаметра, а это обстоятельство, безусловно, относится и к пленочным структурам. При нормальном намагничивании, значение размагничивающего фактора $N_{\mathrm{dem}}$ определяется простым выражением Ndem $=1-c / a$, где $c-$ толщина диска (пленки), а $a$ - его радиус. В этом случае внутреннее поле в сверхпроводнике $H_{i}$ связано с внешним магнитным полем $H_{0}$ равенством $H_{i}=H_{0} \cdot(a / c)$, а коэффициент концентрации магнитного потока на границе сверхпроводника $K=a / c$, который для типичных пленочных структур $(2 a \sim 10 \mathrm{~mm}, c \sim 0.5 \mu \mathrm{m})$ имеет значение порядка $10^{4}$. Это же значение $K$ и было использовано при предварительной оценки чувствительности магнитометра. Однако автору неизвестно ни одного экспериментального подтверждения такой связи величины $N_{p}$ с геометрическими параметрами намагниченного сверхпроводника.

Необходимо отметить, что пленочная структура считается хорошим приближением для эллипсоида вращения при расчете „средних“ значений фактора размагничивания, использующем величину эксцентриситета эллипса. В случае нормального намагничивания возмущения магнитного потока на границах пленки, точнее в непосредственной близости от границ, может существенно отличаться от теоретических расчетов. Нас же, в конечном счете, интересует не „среднее“ значение и даже не величина внутреннего поля, а именно величина возмущения однородного магнитного потока у края сверхпроводниковой пленки и, как следствие, степени затухания этого возмущения по мере удаления от границы. Оценка по различным теоретическим моделям дает для величины нормальной $\left(H_{n}\right)$ и тангенциальной компонент $\left(H_{\perp}\right)$ поля интервал значений $H_{i} \cdot \rho^{-2}<H_{n}$; $H_{\perp}<\rho^{-1} \cdot H_{i}$, где $\rho$ - относительное расстояние, приведенное к толщине пленки, а само значение поля $H_{i}$ лежит в пределах от $(c / a) \cdot H_{0}$ до $(c / a)^{1 / 2} \cdot H_{0}$. Такой разброс степени концентрации магнитного поля, получающийся при расчете $N_{\mathrm{dem}}$ для пленки толщиной $\sim 0.5 \mu \mathrm{m}$ и площадью поверхности $\sim 100 \mathrm{~mm}^{2}$, по разным моделям составляет два порядка, что не позволяет сделать окончательный выбор конкретной схемы построения магнитометра.

Так, при коэффициенте концентрации $K=100$, соответствующему минимальному значению, для достижения чувствительности $10^{-12}$ Т чувствительность измерителя магнитного поля должна составлять $10^{-10} \mathrm{~T}$.

Это, в принципе, практически реальное значение [4], однако, как отмечалось выше, достигнуто оно было с использованием мощного и громоздкого аргонового лазера, таким образом, основная часть проблемы переносится на магнитооптику. Если же $K=10^{4}$, что соответствует максимальному значению, то для
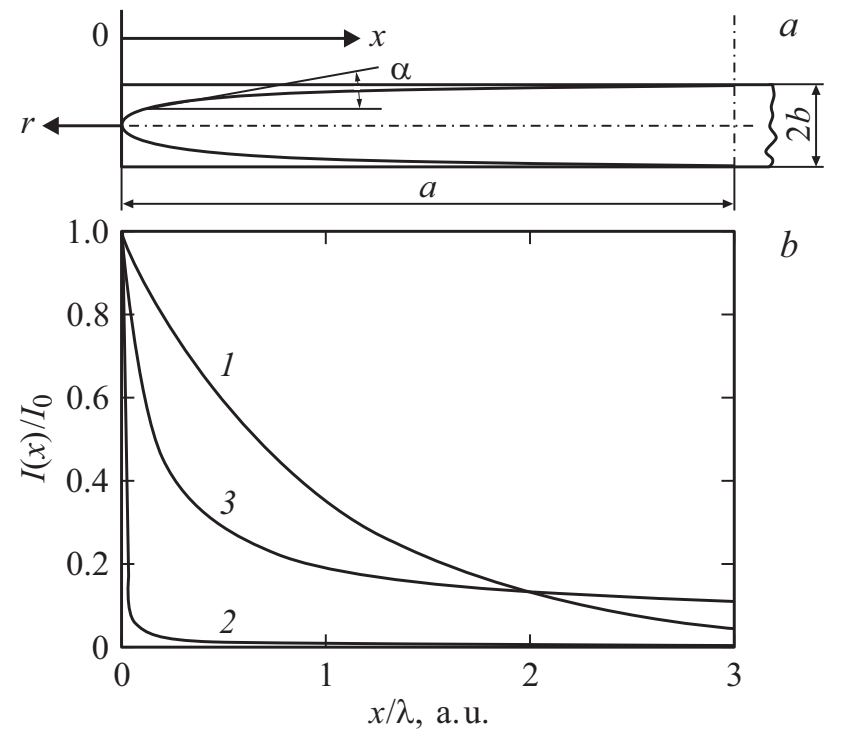

Рис. 5. $a-$ параметры эллипсоида для расчета размагничивающего фактора; $b$ - расчетные распределения плотности тока по поверхности сверхпроводникового сфероида с осями $2 a$ и $2 b: 1$ - затухание тока по экспоненциальному закону, 2 - синусоидальное распределение для пленки $b=0.5 \mu \mathrm{m}$, 3 - для пленки $b=5 \mu \mathrm{m}$.

получения такой же чувствительности магнитометра $\left(10^{-12} \mathrm{~T}\right)$ чувствительность измерителя поля должна составлять $10^{-8} \mathrm{~T}$, что практически реализовано в настоящей работе (см. разд. 3). Таким образом, знание точной величины $K$ или сужение интервала его возможных значений и их связь с геометрическими размерами пленки, становится наиболее важной.

Как отмечалось выше, теоретический расчет фактора размагничивания $N_{\mathrm{dem}}$ возможен только для образцов, имеющих форму эллипсоида. Тонкие круглые пленки хорошо аппроксимируются сфероидом, у которого $2 a=D$, a $2 b=t$, где $D-$ диаметр пленки и $t-$ ее толщина, $\delta=r / a$ - относительная координата (рис. 5).

В нашем случае сфероида с осями $2 a$ и $2 b$, образующей для которого является эллипс, размагничивание происходит благодаря поверхностному току, плотность которого изменяется по закону $I(r)=I(\alpha) \sin \alpha$, где $\alpha-$ угол к поверхности сфероида в точке $r$. В свою очередь угол $\alpha$ связан с параметрами эллипса соотношением

$$
\sin \alpha=(\gamma \delta) /\left[1-\delta^{2}\left(1-\gamma^{2}\right)\right]^{1 / 2},
$$

где $\gamma=b / a$, т.е. отношение малой и большой осей эллипса.

На краю образца изменение плотности тока по закону $\sin \alpha$ должно соответствовать реальному. Исходя из таких представлений, несложными вычислениями можно определить значение эффективного фактора размагничивания $N_{\text {dem }}$, который оказался равным $\left[1-(\lambda / a)^{1 / 2}\right]$, что соответствует $K=(a / \lambda)^{1 / 2}$. Это значение коэффициента концентрации несколько больше нижнего предела, опре- 


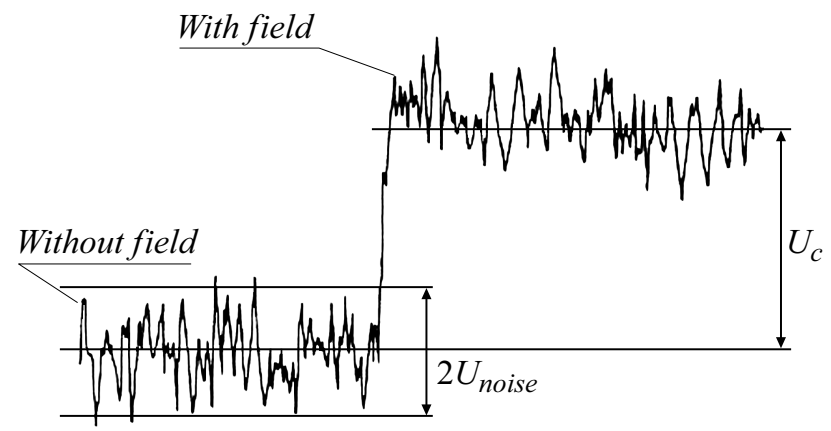

Рис. 6. Сигналограмма регистрации на самописце переменного магнитного поля.

деленного ранее, поскольку для полного экранирования магнитного потока $b \gg \lambda$.

Таким образом, схемное решение построения магнитометра в геометрии прохождения нормально падающего излучения при взаимодействии света с магнитооптической пленкой на длине, равной всего лишь удвоенной толщине пленки при приемлемых параметрах лазерного излучения, не позволяет достичь чувствительности $10^{-12} \mathrm{~T}$.

Существенное увеличение длины взаимодействия было достигнуто за счет волнового распространения света вдоль пленки феррит-граната. Построенный по такой схеме измеритель магнитного поля обладал чувствительностью $10^{-11} \mathrm{~T}[3]$.

\section{3. Малогабаритный магнитооптический измеритель магнитного поля}

Был изготовлен макет малогабаритного измерителя магнитных полей, в котором использовалась магнитооптическая пленка с плоскостной анизотропией. Источник излучения (ИК-светодиод АЛ-119) и приемник (фотодиод ФД-24, смещенный в обратном направлении на активную нагрузку $R=10 \mathrm{k} \Omega$ ), размещались вплотную к магнитооптической пленке. Система катушек подмагничивания 17 (рис. 1) создавала продольное (вдоль оси легкого намагничивания - ОЛН) высокочастотное $(6 \mathrm{kHz})$ и поперечное (вдоль оси трудного намагничивания - ОТН) постоянное магнитные поля. При наложении с помощью катушек Гельмгольца внешнего постоянного поля, перпендикулярного плоскости ЭПФГ $\left(H_{\mathrm{T}}\right)$, плоскость поляризации света повернется на угол $\theta_{\mathrm{F}}$, зависящий от величины внешнего поля. Высокочастотное подмагничивающее поле через специальную катушку создает магнитное поле, параллельное плоскости МО-пленки. В данной геометрии имеется возможность скомпенсировать воздействие относительно большого постоянного поля, перпендикулярного плоскости пленки $H_{\mathrm{T}}$, небольшим по величине плоскостным полем $h$. Ток $I$ в катушке компенсации увеличивается до тех пор, пока плоскостное поле не скомпенсирует воздействие на пленку нормального поля и сигнал с выхода фотоприемника не станет равным нулю. Таким образом, при известной зависимости $h(I)$ определяется величина внешнего поля.

Регистрация сигналов осуществлялась на частоте измеряемых полей $(100-300 \mathrm{~Hz})$ методом синхронного детектирования с выходом на самописец. На рис. 6 представлена характерная сигналограмма в присутствие измеряемого поля и без него.

Изменение постоянного уровня есть полезный сигнал $U_{c}$, а половина размаха шумовой дорожки - дисперсия шума $U_{\text {noise. }}$ При оптимизации датчика отмечено, что режим с одним только высокочастотным подмагничиванием характеризуется высокой чувствительностью к полю, но и очень высоким уровнем шума, подавляющий вклад, в который вносят скачки Баркгаузена. Поперечное постоянное подмагничивание подавляет шумы Баркгаузена. При этом падает и чувствительность магнитометра, однако при небольших полях вдоль ОТН уменьшение шума происходит быстрее. Для использованной пленки оптимальным режимом оказались поперечное магнитное поле $H_{\mathrm{T}}=3 \mathrm{Oe}$, а высокочастотное поле подмагничивания $h=0.2 \mathrm{Oe}$.

При этих параметрах дисперсия шума на входе синхронного детектора составила $0.02 \mu \mathrm{V}$, что эквивалентно измеряемому полю $0.3 \cdot 10^{-4}$ Ое при времени интегрирования $1 \mathrm{~s}$. Для оценки качества макета магнитометра, т.е. близости его характеристик к предельно достижимым в данной схеме, был оценен уровень дробовых шумов схемы, который составлял $V_{\text {shot }}=0.023 \mu \mathrm{V} / \mathrm{Hz}^{1 / 2}$. Таким образом, чувствительность представленного магнитометра ограничена практически дробовыми шумами и, следовательно, является предельной для используемого ИК-светодиода.

\section{4. Магнитометр с пространственной модуляцией плотности магнитного потока}

В работах [5,6] были представлены исследования по преобразованию оптических мод в планарных волноводах на основе феррит-гранатовых пленок. Для управления волноводным излучением волноводная пленка намагничивалась внешними периодическими полями, обеспечивающими выполнения условий брэгговской дифракции. Период изменения внешнего поля (период решетки) $d=2 \pi / k$, где $k=\left(\beta_{\mathrm{TE}}^{2}-\beta_{\mathrm{TM}}^{2}\right)^{1 / 2}-$ разность в постоянных распространения двух волноводных мод, взаимодействие между которыми необходимо обеспечить. Величина $k$ может изменяться от единиц до десятков или даже тысяч обратных сантиметров в зависимости от толщины пленки, показателей преломления пленки и подложки и номера взаимодействующих мод. Минимальный период решетки принципиально ограничивается только толщиной рабочего слоя пленки ЭПФГ. Максимальное значение $k$ составляло $\sim 5000 \mathrm{~cm}^{-1}$. 
Преобразование волноводных мод происходит за счет эффекта Фарадея по закону

$$
I_{\mathrm{F}}=I_{0} \sin ^{2}\left(æ \theta_{\mathrm{F}}\right) \cdot l,
$$

где $\theta_{\mathrm{F}}$ - удельное фарадеевское вращение, æ - коэффициент, зависящий от характера распределения магнитного поля, $l$ - длина взаимодействия, $\varphi_{\mathrm{F}}-$ угол поворота плоскости поляризации, $\varphi_{\mathrm{F}}=V \cdot l \cdot H, V-$ постоянная Верде. Для используемой в настоящей работе ЭПФГ $V=7.2$ degree $/ \AA$.

В коллинеарном режиме преобразования $\mathrm{TE}_{0} \rightarrow \mathrm{TM}_{0}$ величина $d=0.7 \mathrm{~mm}$. Практически $100 \%$ эффективность преобразования была получена на длине взаимодействия $l \sim 1 \mathrm{~mm}$ в полях напряженностью 10 Ое. При увеличении длины взаимодействия до $10 \mathrm{~mm}$ полное преобразование мод происходит в полях, не превышающих 1 Oе. Этот результат позволяет оценить чувствительность измерителя магнитного поля, построенного по принципу преобразования мод, которая может достичь значения $10^{-11}$ T. Чувствительность же магнитометра в целом будет зависеть от степени концентрации магнитного потока ВТСП пленкой.

Для обеспечения условия согласования мод [7] в настоящей работе была изготовлена ВТСП структура матричного типа с размером ячеек $300 \mu \mathrm{m}$ и расстоянии между ними $60 \mu \mathrm{m}$. Общая длина составляла $0.96 \mathrm{~cm}$. Измерения проводились на феррит-гранатовых пленках состава $(\mathrm{YbPrBiGd})_{3}(\mathrm{FeAl})_{5} \mathrm{O}_{12}$ на подложке из галлий-гадолиниевого граната (ГГГ). Толщина пленки $2.1 \mu \mathrm{m}$, показатель преломления $n_{\text {film }}=2.25$, удельное фарадеевское вращение на длине волны $\lambda=1.15 \mu \mathrm{m}$, $\theta_{\mathrm{F}}=30 \mathrm{rad} / \mathrm{cm}$. Показатель преломления подложки $n_{\text {sub }}=1.94$. Для управления волноводным излучением пленка феррит-граната намагничивалась с помощью матрицы ВТСП внешними периодическими полями.

Наибольшая чувствительность к преобразованиям достигается при равенстве интенсивностей падающей и преобразованной мод т.е. при $\mathfrak{F}_{\mathrm{F}}=\pi / 4$ (рис. 7,a). На рис. 7, $b$ представлено состояние намагниченности МО-пленки периодическим полем с периодом $360 \mu \mathrm{m}$.

Использование дифференциального приема становится возможным благодаря пространственному разделению ТЕ и ТМ мод, что позволяет избавиться от флуктуаций интенсивности излучения лазера и увеличить полезный сигнал в два раза. Проведенные измерения показали, что коэффициент концентрации магнитного потока каждой ячейки составлял около 40. Чувствительность же такого магнетометра по самым скромным оценкам должна быть не хуже $10^{-12} \mathrm{~T}$ при измерении как постоянных, так и переменных магнитных полей.

Принципиальная схема магнетометра, построенного по способу периодической пространственной модуляции плотности магнитного потока многоэлементной ВТСП структурой с использованием планарного феррит-гранатового волновода в качестве измерителя магнитного поля, приведена на рис. 8.

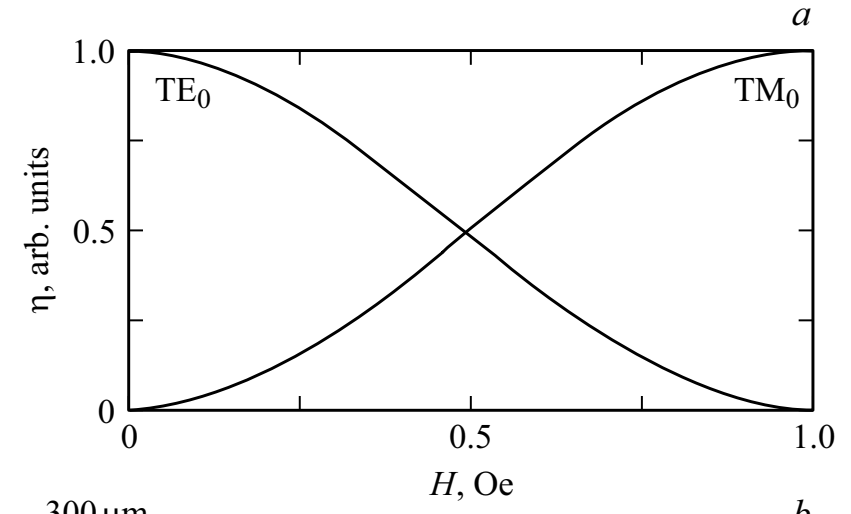

\section{$300 \mu \mathrm{m}$ \\ b}

$H, \mathrm{Oe}$

Рис. 7. $a-$ преобразование $\mathrm{TE}_{0} \rightarrow \mathrm{TM}_{0}$ в планарном магнитооптическом волноводе; $b$ - состояние намагниченности ЭПФГ периодическим полем с периодом $360 \mu \mathrm{m}$, соответствующий коэффициенту преобразования $\eta=1.0$.

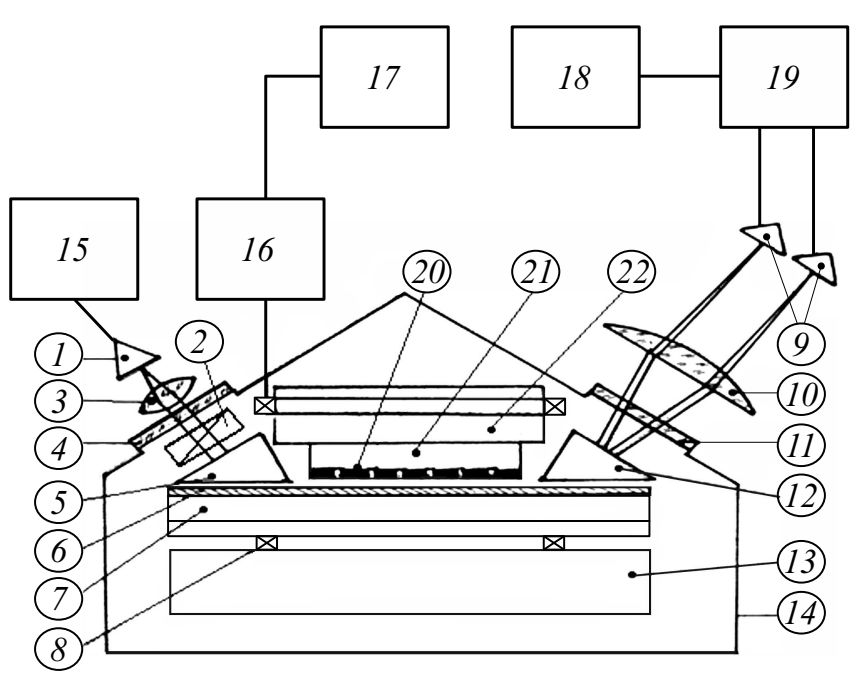

Рис. 8. Принципиальная схема магнитометра с концентратором из периодической ВТСП структуры в виде матрицы. 1 - полупроводниковый лазер $(\lambda=1.3 \mu \mathrm{m}) ; 2$ - кристаллический поляризатор; 3,10 - объективы; 4, 11 - кварцевые окна; 5, 12 - призмы из GaP; 6 - ЭПФГ с плоскостной анизотропией; 7 - подложка из галлий-гадолиниевого граната (ГГГ); 8 - катушка высокочастотного подмагничивания; 9 - дифференциальный фотоприемник; 13, 22 - хладопровод; 14 - оболочка криостата; 15 - питание лазера; 16 - питание катушек Гельмгольца; 17 - управление током подмагничивания; 18 - устройство отображения; 19 - дифференциальный усилитель; 20 - матрица ВТСП; 21 - подложка.

Для ввода и вывода излучения использовались призмы из $\mathrm{GaP}(n=3.1)$. Материал призм был выбран из следующих соображений: показатель преломления призм должен быть больше показателя преломления волноводной пленки и быть прозрачным для лазерно- 
го излучения. Излучение лазера проходит через высокодобротный $\left(Q=10^{3}\right)$ кристаллический поляризатор, ориентированный так, чтобы излучение входило в пленку в виде ТЕ моды, плоскость поляризации которой перпендикулярна плоскости лабораторного стола. Лазер располагался так, что плоскость поляризации выходного излучения была наклонена к плоскости стола под углом $45^{\circ}$, что позволяло вводить ТЕ и ТМ поляризации равной интенсивности при соответствующем повороте входного поляризатора. Далее излучение проходит через цилиндрическую линзу, формируется на входной линейный контакт и распространяется в пленке в виде волноводной ТЕ 0 моды. На выходе из выводной призмы в случае дифракции имеются 2 пучка - прошедший и дифрагированный, - которые поступали на дифференциальный фотоприемник и далее на устройство отображения.

\section{Заключение}

На основании проведенных исследований предложена принципиальная схема построения магнитометра для измерения малых магнитных полей $\left(\sim 10^{-12} \mathrm{~T}\right)$ по способу периодической пространственной модуляции плотности магнитного потока многоэлементной ВТСП структурой и его последующего измерения планарным магнитооптическим устройством. Общая чувствительность магнитометра, построенного по принципу периодической пространственной модуляции плотности магнитного потока многоэлементной ВТСП структурой с использованием пленочного феррит-гранатового волновода в качестве измерителя магнитного поля, должна быть не хуже $10^{-12} \mathrm{~T}$, и по этому параметру уступает лишь СКВИДу, обладая, вместе с тем возможностью измерять как постоянные, так и переменные магнитные поля.

В ходе исследований была рассмотрена также методика измерения концентрированного магнитного потока у края сплошной ВТСП пленки с помощью феррит-гранатовой пленки с одноосной анизотропией, расположенной перпендикулярно торцу сэндвича „подложка-ВТСП пленка“. При этом край подложки, на которую была напылена ВТСП пленка, должен быть обработан с оптической точностью, так как именно этим будет определяться чувствительность магнитометра. В этом случае феррит-гранатовая пленка должна обладать минимальной коэрцитивностью. Измерение напряженности магнитного поля в таком варианте производится по изменению естественной доменной структуры в области локализации магнитного потока оптической схемой с высокой разрешающей способностью. Компонента магнитного поля нормальная к поверхности феррит-гранатовой пленке имеет знакопеременный характер и позволяет использовать для целей измерения дифференциальный фотоприемник, расположенный в плоскости изображения. Недостатком этого метода является относительная сложность оптической системы регистрации и необходимость установки микрообъектива в непосредственной близости от ВТСП пленки, т.е. внутри азотного криостата. Тем не менее реализовать подобную схему нам не удалось по причине отсутствия необходимой технологии обработки торца сэндвича „подложка-ВТСП пленка“ с оптической точностью.

\section{Финансирование работы}

Работа поддержана Программой повышения конкурентоспособности Национального исследовательского ядерного университета „МИФИ“.

\section{Список литературы}

[1] Есиков О.С., Протасов Е.А. // Инженерная физика. 1999. № 2. C. 8 .

[2] Протасов Е.А. // ЖТФ. 2018. Т.88. Вып. 8. С. 1229-1234.

[3] Doriath G., Gandry R., Hartemann A. // J. Appl. Phys. 1982. Vol. 53. N 11. P. 8263-8265.

[4] Ветошко П.М., Топоров А.Ю. // В кн.: Х11 Всесоюзный семинар „Новые магнитные материалы микроэлектроники“. Тезисы докладов. Новгород. 1990. С. 234-235.

[5] Есиков О.С., Каменьщиков Д.Г. // Письма в ЖТФ. 1987. Т. 13. Вып. 8. С. 468-471.

[6] Есиков О.С., Каменьщиков Д.Г. // Письма в ЖТФ. 1989. Т. 15. Вып. 4. С. 81-84.

[7] Ярив А.В. // Введение в интегральную оптику. Под ред. Барнески. М.: Мир, 1977. С. 176. 